\title{
Personal, Situational and Socio-Cultural Factors as Correlates of Intimate Partner Abuse in Nigeria
}

\author{
David Oladeji \\ Department of Family, Nutrition and Consumer Sciences, Obafemi Awolowo University Ile-Ife, Ile-Ife, Nigeria \\ Email: dijideji@yahoo.co.uk
}

Received July 24, 2013; revised August 24, 2013; accepted September 1, 2013

Copyright (C) 2013 David Oladeji. This is an open access article distributed under the Creative Commons Attribution License, which permits unrestricted use, distribution, and reproduction in any medium, provided the original work is properly cited.

\begin{abstract}
This study established the relationships between personal, situational and socio-cultural factors and intimate partner abuse among couples in Nigeria. A multiple regression statistical procedure was employed in analyzing the data collected from 200 participants randomly selected from five ministries in Ibadan, Oyo state, Nigeria. Results obtained indicated that the three variables when combined effectively predicted intimate partner abuse (F-ratio of 5.756 significant at 0.05 alpha level). Taken separately, situational and socio-cultural factors contributed significantly to the prediction $(t$ $=2.146, p<0.05 ; t=2.284, p<0.05)$, while personal factor did not $(t=1.705, p>0.05)$. On the basis of these findings it was suggested that counselling psychologists should design intervention strategies to promote life-skills training in schools and out-of-schools settings. These include age-appropriate content on sexuality, conflict resolution, building healthy relationships and personal safety. Also, it was suggested that couples should be informed on the long-term health and social consequences of physical and sexual abuse.
\end{abstract}

Keywords: Personal; Situational; Socio-Cultural; Partner Abuse; Nigeria

\section{Introduction}

Violence against women is the most persuasive yet least recognised human rights abuse in the world. It also is a profound health problem, sapping women's energy, compromising their physical health, and eroding their self esteem. Despite its high costs, almost every society in the world has social institutions that legitimize, obscure, and deny abuse. The same acts that will be punished if directed at an employer, a neighbour, or an acquaintance often go unchallenged when men direct them at women, especially within the family.

For over two decades women's advocacy groups around the world have been working to draw more attention to the physical, psychological, and sexual abuse of women and to stress the need for action. They have provided abused women with shelter, lobbied for legal reforms, and challenged the widespread attitudes and beliefs that support violent behaviour against women [1].

Increasingly, these efforts are having results. Today, international institutions are speaking out against gender based violence. Surveys and studies are collecting more information about the prevalence and nature of abuse. More organizations, service providers, and policy-makers are recognising that violence against women has serious adverse consequence for women's health and for society.

A growing number of reproductive health programs and practitioners understand that they have a key role to play addressing violence, not only in helping individual victims but also in preventing abuse. As more becomes known about the scope of gender-based violence and the reasons behind it, more programs are finding ways to address it.

Violence is a regular part of most women's experience in Nigeria, especially at homes intended to nurture the psychological upliftment and development of its members. Domestic violence refers to violence within the home. It is carried out mostly against women and children. These acts include rape (forced sex); physical abuse; verbal abuse; incest; Female Genital Cutting (FGC); denial of food; denial of time for relaxation; forced marriage and child marriage [2]. For the purpose of this study, intimate partner abuse/violence is defined as the European Council of Ministers suggests: Any act or omission committed within the framework of the family, by one of its members, that undermines the life, the bodily or psychological integrity, or the liberty of another member of the same family, or that seriously harms the development of his or her personality. 
Intimate partner violence is increasingly recognized as an important social and public health problem and a violation of human rights. According to the 2008 Nigeria Demographic and Health Survey, 18 percent of ever married women had experienced intimate partner physical violence, 4 percent had experienced intimate partner sexual violence, and 24 percent had experienced intimate partner emotional violence at least once in their life time. Of women who had ever been pregnant, 5 percent had experienced physical violence during pregnancy. The highest rates of violence victimization in the current union or most recent union, regardless of the type of violence, were found in the South (46\%), North Central (38\%), and south East (35\%) zones [3].

\section{Review of Related Literature}

Physical violence in intimate relationships almost always is accompanied by psychological abuse and, in one-third to over one-half of cases, by sexual abuse ([4-8]). For example, among 613 abused women in Japan, 57\% has suffered all the three types of abuse-physical, psychological and sexual. Only $80 \%$ has experienced physical abuse alone [9]. In Montererry, Mexico, 52\% of physically abused women had also been sexually abused by their partners [10]. In Leon, Nicaragua, among 100 women who were physically abuses by their partners, only 5 were not also abused seually, psychologically or both [6].

Most women who suffer any physical aggression generally experience multiple acts over time. In Leon study, for example, $60 \%$ of woman abused in the previous year were abused more tahn once, and $20 \%$ experienced severe violence more than six times. Among women reporting any physical aggression, 70\% reported severe abuse [6]. The average number of physical assaults in the previous year among currently abused women surveyed in London was seven [11]; in the united states in 1997, three [12].

Many cultures hold that men have the right to control their wives behaviour and that women who challenge that right-even by asking for household money or expressing the needs of the children- may be punished. In countries as different as Bangladesh, Cambodia, India, Mexico, Nigeria, Pakistan, Paupa, new Guinea, Tanzania, and Zimbabwe, studies find that violence is frequently viewed as physical chastisement-the husband's right to "correct” an erring wife [13-19]. As one husband said in focus-group discussion in Tamil Nadu, India, "If it is a great mistake, then the husband is justified in beating his wife." Why not? A cow will not be obedient without beating [14].

Justification for violence frequently evolves from gender norms- that is, social norms about the proper roles and responsibilities of men and women [13]. Typically, men are given relatively free reign as long as they pro- vide financially for the family. Women are expected to tend to house and mind the children and to show their husbands obedience and respect. If a man perceives that his wife has somehow failed in her role, stepped beyond her bounds or challenged his rights, then he may react violently.

Worldwide, studies identify a consistent list of event(s) that are said to "trigger" violence. These includes: not obeying her husband, talking back, not having food ready on time, failing to care adequately for the children or home, questioning him about money or girlfriends, going somewhere without his permission, refusing him sex, or expressing suspicious of infidelity ([14-22]. All of these constitute transgression of gender norms. Even where culture itself grants men substantial control over female behaviour, abusive men generally exceed the norm (Rosales-Ortiz, Loaiza, Primate, Baberena, Blandon-Sequiera \& Ellsberg, 1999; [23-25]. For example, data from the Nicaragua Demographic and Health survey (DHS) show that, among women who were abused physically, 32\% had husbands who scored high on a scale of marital control compared with only $2 \%$ among women who were not abused physically. The scale included such behaviour as the husbands continually accussing his wife of being unfaithful and limiting her access to family and friends [23].

Understanding the interplay of personal, situational, and socio-cultural factors that combine to cause abuse would involve using ecological framework [26]. This framework results from the interaction of factors at different levels of the social environment. A wide range of studies agrees on several factors at each of these levels that increase the likelihood that a man will abuse his partner:

- At the personal or individual level these include being abused as a child or witnessing marital violence at home [27,28], having an absent or rejecting father [29], and frequent use of alcohol [27,30-34].

- At the level of the family relationship, cross-cultural studies have cited male control of wealth and decision-making within the family [31]; and marital conflict as strong predictors of abuse [35].

- At the community level women's isolation and lack of social support, together with male peer groups that condone and legitimize men's violence, predicted higher rates of violence ([31,36,37]).

- At the societal level studies around the world have found that violence against women is most common where gender roles are rigidly defined and enforced [26] and where the concept of masculinity is linked to toughness, male honour or dominance [13]. Other cultural norms associated with abuse include tolerance of physical punishment of women and children, 
acceptance of violence as a means of settle interpersonal disputes and the perception that men have

“owner-ship” of women [26,27,38,39].

Most studies on domestic violence and marital abuse in particular focused on perception, attitudes, and practices. It is not to the knowledge of the researcher therefore that studies linking the interaction of personal, situation and socio-cultural factors as predictors of intimate partner abuse had been done. It is against this background that this study becomes relevant in filling such missing gaps in our knowledge in the issue of personal, situational and socio-cultural factors and intimate partner abuse among couples in Nigeria.

\section{Purpose of This Study}

This study examined the relationship between personal, situational and socio-cultural factors and intimate partner abuse among couples in Nigeria.

In order to achieve the purpose of this study, the following research questions were answered:

1) To what extent would personal, situational and socio-cultural factors when combined predict intimate partner abuse in Nigeria?

2) What is the relative contribution of the factors to the prediction of intimate partner abuse in Nigeria?

\section{Methodology}

\subsection{Design}

This study employed a descriptive research design in which data were collected through questionnaire from the respondents on the variables studied.

\subsection{Participants}

A total of two hundred (200) participants were randomly drawn from five ministries in Oyo State. They included Ministry of Education-fifty (20 males representing 10\%; 30 females representing 15\%), Ministry of Finance- fifty (22 females representing 11\%; 18 males representing 9\%), Ministry of Health-fifty (16 males representing 8\%; 24 females representing 12\%), Ministry of Women Affairs-50 females representing 25\% and Ministry of Justice-fifty (28 females representing 14\%; 12 males representing 6\%). The range of participants' age was between 30 and 46 with a mean of 38.0 and a standard deviation of 11.3. All the participants were literates, married for a minimum of 5years and with a minimum qualification of School Certificate Education to University Education.

\subsection{Instrumentation}

The four instruments used to collect data for the study were: 1) Personal Factor Scale (PFS); 2) Situational Factor Scale (SFS); 3) Socio-cultural Factor Scale (SFS); 4) Marital Conflict Tactics Scale (MCTS) by Dobash and Dobash (1992). The first three instruments were authorconstructed.

1) Personal factor scale (PFS): this scale measures the level of abuse on the child, having a rejected father, and frequent use of drugs and alcohol. It is made up of 10 items rated on a 5-point Likert-type scale. The respondents are to indicate their degree of agreement with each item by ticking Strongly Disagree $(\mathrm{SD})=1$; Disagree (D) $=2$; Neutral $(\mathrm{N})=3$; Agree $(\mathrm{A})=4$; Strongly Agree $(\mathrm{SA})$ $=5$. It has 0.75 and 0.78 as the internal consistency and revalidation reliability respectively.

2) Situational Factor Scale (SFS): the scale measures male control of wealth, decision-making within the family and marital conflict. It has 10 items with true and false response format. It has 0.80 as the internal consistency and a test-retest reliability of 0.85 .

3) Socio-cultural Factor Scale SFS: the scale has 10 items to which respondents are to circle either a) Partly true, b) Mostly true, c) Partly untrue, d) Mostly untrue, e) Very untrue as the item applies to them. The scale measures women's isolation, lack of social supports and perception that men have "ownership" of women, the testretest reliability of the scale was found to be 0.84 and 0.86 respectively.

4) Marital Conflict Tactics Scale (MCTS) by Dobash and Dobash (1992). The scale measures the nature, pattern and prevalence of family violence. It is made up of 20 items rated on a 4-point Likert-type scale. The respondents are to indicate their agreement with each item by ticking Very True $(\mathrm{VT})=(4)$; True $(\mathrm{T})=(3)$; Hardly True $(\mathrm{HT})=(2)$; and Not True $(\mathrm{NT})=(1)$. The internal consistency of the scale as reported by Dobash and Dobash (1992) was 0.79, while the test-retest reliability of the scale (MCTS) among 50 Nigerian samples was 0.84 .

All the four instruments were considered valid through the favourable comments of experts in psychometrics on the suitability of the items.

\subsection{Procedure}

The participants for the study were administered the four questionnaire namely; Personal Factor Scale, Situational Factor Scale, Socio-cultural Factor Scale and marital Conflicts Tactics Scale in their respective ministries. The collected questionnaires were scored and the data obtained from them were analysed to answer the research questions.

\section{Data Analysis}

Data Analysis involved using Multiple Regression analysis procedure to examine the relationship between Inti- 
mate Partner Abuse (dependent variable) and personal, situational and socio-cultural factors (independent variables).

\section{Results}

\subsection{Research Questions 1}

Using a combination of the independent variables to predict intimate partner abuse.

Table 1 showed that the combination of the three independent variables (Personal factor, situational factor and socio-cultural factors) in predicting intimate partner abuse gave a coefficient of multiple regression (R) of 0.258 and a multiple R-square $\left(\mathrm{R}^{2}\right)$ of 0.066 accounting for $6.6 \%$ of the variance in intimate partner abuse. The table also shows that the analysis produced the Fishers value F-ratio of 5.756 significant at 0.05 alpha level.

\subsection{Research Question 2}

Relative contribution of independent variables to the prediction of intimate partner abuse.

The results on Table 2 indicates that the standardized regression coefficients (Beta) ranged from 0.111 to 0.146 , unstandardized regression coefficient ranged (B) from 0.278 to 0.103 , standard error of estimate ranged from 0.163 to 0.045 , t-ratios ranged from 1.705 to 2.284 and that two variables situational and socio- cultural factors were significant at 0.05 alpha level while personal factors was not significant.

\section{Discussion}

The results obtained from this study indicated that three independent variables (personal, Situation and socio-cultural factors) when taken together were effective in the prediction of intimate partner abuse among couples. The observed F-ratio of 5.756, significant at 0.05 alpha level is an evidence that the effectiveness of a combination of the independent variables in the prediction of intimate abuse could not have occurred by chance. Furthermore, the coefficient of multiple correlate of 0.258 and a multiple R-square of 0.66 showed the magnitude of the relationship between intimate partner abuse and the combination of the independent variables. The results indicated that a linear relationship of the independent variables accounted for only $6.66 \%$ of the total variance in intimate partner abuse among couples.

The result on Table 2 revealed that the contribution made by each independent variable to the prediction of intimate partner abuse is shown on the table. The t-ratio values associated with each independent variable showed that situational factors contributed significantly to the prediction while personal factors did not.

Based on the above result, situational factors are the
Table 1. Summary of regression analysis on sample data (Analysis of Variance).

\begin{tabular}{ccccccc}
\hline $\begin{array}{c}\text { Source of } \\
\text { Variation }\end{array}$ & SS & Df & MS & F & P & Remark \\
\hline Regression & 6151.269 & 3 & 2050.423 & 5.756 & 0.05 Sig. \\
Residual & 86556.772 & 196 & 356.201 & & \\
Total & 92708.040 & 199 & & & \\
\hline
\end{tabular}

Multiple $R=0.258$; Multiple $R$-Square $=0.066$; Standard Error of Estimate $=18.87$.

Table 2. Testing the significance of relative contribution to the prediction of regression weights of independents variables.

\begin{tabular}{ccccccc}
\hline & \multicolumn{7}{c}{ Unstandardized Standardized } & & \\
Variable & \multicolumn{2}{c}{ Coefficients } & Coefficients & & & \\
\cline { 2 - 4 } Description & B & $\begin{array}{c}\text { Std. } \\
\text { Error }\end{array}$ & Beta & & Remark \\
\hline $\begin{array}{c}\text { Personal factors } \\
\begin{array}{c}\text { Situational } \\
\text { factors }\end{array}\end{array}$ & 0.278 & 0.163 & 0.111 & 1.705 & NS \\
$\begin{array}{c}\text { Socio-cultural } \\
\text { factors }\end{array}$ & 0.103 & 0.045 & 0.146 & 2.284 & 0.05 & Sig. \\
Constant & 40.904 & 7.634 & & 5.385 & 0.000 \\
\hline
\end{tabular}

most important predictor of intimate partner abuse. The results agree with the findings reported by [16,24,28]. These findings suggest that violence frequently evolve from gender norms, that is, social norms about the proper roles and responsibilities of man and woman [6].

Another finding from this study revealed worldwide, studies identify a consistent list of events that are said to "trigger" violence. These include: not obeying her husband, talking back, not having food ready on time, failing to care adequately for the children or home, questioning him about money or girlfriends, going somewhere without his permission, refusing him sex or expressing suspicious of infidelity $([13,18,26,30,34,36,38])$.

\section{Implications for Counselling}

Although personal factors was not found to significantly predict intimate partner abuse in the samples involved in this study, attention of the Guidance Counsellors, should be directed to personal factors of the couples because they are part of the situational factors of the couples because they are part of the situational factors that are antecedent to intimate partner abuse attempts. Related to this is the point of view of [29]; Moreno- Martin, 1999; $[14,24]$; that intimate abuse is a reflection of more permanent inability to form a partner decision, rooted in a personality disorder including personal factors.

The findings from the study have implications for Guidance Counsellors, Psychologists, Social Workers 
and Welfares and others in the helping professions among couples and social relationships. First, there is need for the professional helpers mentioned above to identify the variables such as personal, situational and socio-cultural factors among couples because these variables relate to intimate partner abuse. Once these variables are identified through assessment and personal counselling giving appropriate intervention assistance to couples having partnership problems will be possible.

Secondly, couples and those within the reproductive age should be made to participate in individual and group counselling experience to foster their interpersonal maturity involving tolerance, trust, intimacy, and co-operative interdependence without losing their autonomy.

Finally, further interventions for marital conflicts should take into consideration the psychological and social resources that the couples and those of reproductive age often face, survey their preferred channels of information and communication and thereafter provide ample dissemination strategies that would foster positive change.

\section{Recommendations and Suggestions}

The following recommendations may go a long way to address intimate partner abuse among couples in Nigeria.

- Workshops and campaigns should be organized to delegitimize violence as a way to resolve conflict or to "discipline" women or children.

- Highlight the prevalence of abuse and its cost to families and society (e.g. impact of witnessing violence in childhood).

- The civil society, religious bodies, and concerned citizen should promote supportive responses (not blaming) to victims of physical or sexual abuse, using street theatre, alternative media, and public education campaigns.

- The Government, Non- Governmental organizational, the civil society should promote human rights, education and other ways to empower women.

- The Government and the Educators should provide comprehensive sexuality education including exercises that examine gender norms, double standards for male and female sexual behaviour; role-playing on resisting pressure to engage in unwanted sexual behaviour.

- Enable boys and girls (first separately, then in mixed groups) to discuss relationships, love, anger, jealousy, and abuse. Educate young women about their rights.

- Promote an ethic of care so that couples see themselves as responsible for the whole persona, not just the person's symptoms.

- Promote life-skills training in schools and out-ofschool settings; include age-appropriate content on sexuality, conflict resolution, building healthy rela- tionships and personal safety.

\section{Acknowledgements}

The author wish to appreciate the respondents for their honesty in filling the questionnaires and also thank the research assistants for sparing their time in the administration, collation and collection of the administered questionnaire. Also, acknowledged are the two analysts in the interpretation of data collected. I wish them all good luck in their endeavours.

\section{REFERENCES}

[1] J. P. Clark and M. J. Du, "Intimate Partner Violence and Health: A Critique of Canadian Prevalence Studies,” Canadian Journal of Public Health, Vol. 94, No. 1, 2003, pp. 52-58.

[2] A. Joda, H. Zubairu, G. A. Abdulawaheeds and R. Abara, “Against Violence against Women,” Baobab Legal Literacy Leaflet No. 1, 2007.

http://www.baobabwomen.org/AVAW.doc

[3] National Population Commission and ICF Macro, "Interview with a Human Right Defender Who Campaigned to end Violence against Women in Family,” Lagos State, 2009.

[4] J. Campbell, and K. Soekan, "Forced Sex and Intimate Partner Violence. Effects on Women Risk and women's Health,” Violence against Women, Vol. 5, No. 9, 2002, pp. 1017-1035.

[5] Centre for Health and gender Equity, "Mental Health and Behavioural Outcomes of Sexual Abuse: Data Summary," Maryland Change, Takoma Park, 2001.

[6] D. G. Dutton, "Domestic Assault of Women: Psychological and Criminal Justice Perspective,” University of British Colombia Press, Vancouver, 1995, p. 337.

[7] J. Leibrich, J. Paulin and R. Ransom, "Hitting Home: Men Speak about Domestic Abuse of Women Partners," Wellington, 1995.

[8] M. P. Koss, I. A. Goodman, A. Browne, I. F. Fitzgerald, G. P. Kelta and N. F. Russo, "No Safe Haven: Male Violence against Women at Home, at Work, and in the Community," American Psychological Association, Washington DC, 1994. http://dx.doi.org/10.1037/10156-000

[9] M. Yoshihama and S. B. Sorenson, "Physical, Sexual and Emotional Abuse by Male Intimate: Experiences of Women in Japan," Violence and Victims, Vol. 9, No. 1, 2000, pp. 63-77.

[10] M. G. Shiroma, "Salud Reproductive Violence Contra la Mujer: Reproductive Health and Violence against Women: An Analysis from a Gender Perspective,” 2004, p. 42.

[11] J. Mooney, "Hidden Figure: Domestic Violence in North London,” Middlesex University, London, 2001.

[12] Tjanen and N. Thoennes, "Prevalence Incidence and Consequences of Violence against Women,” Findings from the National Violence against Women Survey, National Institute of Justice CDC, Washington DC, 2002. 
[13] S. Contzalez-Montes, "Domestic Violence in Cuetzalan, Mexico. Some Research Questions and Results,” Centre for Health and Gender Equity Network on Violence against Women, 1998, pp. 30-41.

[14] S. J. Jejebhoy, "Wife Beating in Rural India: A Husband's Right?” Economic and Political Weekly (India), Vol. 23, No. 15, 1998, pp. 588-862.

[15] L. Michau, "Community-Based For Social Change in Muanza, Tanzania,” Centre for Health and Gender Equity, International Research Network on Violence against Women, Washington DC, 1997, pp. 4-9.

[16] G. Osakue and A. M. Hilber, "Women's Sexuality and Fertility in Nigeria,” In: R. Petchesky and K. Judd, Eds., Negotiating Reproductive Rights, 2nd Edition, Book Ltd., London, 1998, pp. 180-216.

[17] S. R. Schuler, S. M. Hashemi, A. P. Riley and S. Akheter, "Credit Programmes, Patriarchy and Men's Violence against Women in Rural Bangladesh,” Social Science and Medicine, Vol. 43, No. 12, 1996, pp. 1729-1742. http://dx.doi.org/10.1016/S0277-9536(96)00068-8

[18] K. Zimmerman, "Plates in Basket Will Rattle: Domestic Violence in Cambodia," Cambodia Project against Domestic Violence, 1995.

[19] Y. Hassan, "The Haven Becomes Hell: A Study of Domestic Violence in Pakistan,” Women Living under Muslim Laws, 1995, p. 72.

[20] L. Visaria, "Violence against Women in India: Evidence from Rural Gujarat in Domestic Violence in India,” International Centre for Research on Women, Washington DC, 1999, pp. 9-17.

[21] A. Armstrong, "Culture and Choice: Lessons from Survivors of Gender Violence in Zimbabwe,” Harare. P. 149, 2000.

[22] M. Fournier, R. D. Rios, P. Orpinas and L., PiquetCarneiro, "Multicentre Study on Cultural Attitudes and Norms towards Violence," Revista Panamericana de Salud Publica, Vol. 5, No. 4, 1999, pp. 222-231.

[23] J. Rosales, E. Loaiza, D. Primante, A. Barberena, L. B. Sequeira and M. Ellsberg, "Encuesta Nicaraguense de Demografia y Salud,” 1998.

[24] H. Johnson, "Dangerous Domains: Violence against Women in Canada," Nelson Canada Publishing, Ontario, 1996, p. 252.

[25] M. Romero, "Sexual and Domestic Violence: Report from the Qualitative Phase from an Adolescent Centre in san-Niguel de,” Population Council, Mexico City, 1994, p. 53.

[26] L. Heise, "Violence against Women: An Integrated Ecological Framework,” Violence against Women, Vol. 4, No. 3, 1998, pp. 262-290. http://dx.doi.org/10.1177/1077801298004003002

[27] M. Fournier, R. D. Rios, P. Orpinas and L., PiquetCarneiro, "Multicentre Study on Cultural Attitudes and
Norms towards Violence," Revista Panamericana de Salud Publica, Vol. 5, No. 4, 1999, pp. 222-231.

[28] G. T. Hotalling and D. B. Sugarman, “An Analysis of Risk Markers in Husband to Wife Violence: The Current State of Knowledge,” Violence and Victims, Vol. 1, No. 2, 1986, pp. 101-124.

[29] D. Counts, J. K. Brown and J. C. Campbell, "Sanctions and Sanctuary: Cultural Perspectives on the Beating of Wives,” West-view Press, Boulder, 1992, p. 337.

[30] O. N. Kyriacou, F. Mccabe, D. Anglin, K. Lapesarde and M. R. Winer, "Emergency Department-Based on the Study of Risk Factors for Acute Injury from Domestic Violence against Women,” Annals of Emergency Medicine, Vol. 3, No. 4, 1998, pp. 502-506. http://dx.doi.org/10.1016/S0196-0644(98)70261-6

[31] R. S. Oropesa, "Development and Marital Power in Mexico," Social Forces, Vol. 75, No. 4, 1997, pp. 1292-1317.

[32] C. Parry, J. Tibbs, J. Vanderspuy and G. Cummins, "Alcohol Attributable Fractions for Trauma in South Africa," Curationis, Vol. 19, No. 1, 1996, pp. 2-5.

[33] J. Mccauley, D. E. Kern, K. Kolodnr, L. Dil, A. F. Schroeder, H. K. Dechant, J. Ryden, E. B. Bass and L. R. Derogatis, “The Battering Syndrome," Prevalence and Clinical Characteristics of Domestic Violence In Primary Health Care Internal Medicine Practices, Annals of Internal Medicine, Vol. 123, No. 10, 1995, pp. 737-746. http://dx.doi.org/10.7326/0003-4819-123-10-199511150$\underline{00001}$

[34] J. T. Bertrand, V. Ward and F. Pauc, "Sexual Practices among the Quiche-Speaking Mayan Population of Guatamab," International Quarterly of Communication Health Education, Vol. 12, No. 4, 1992, pp. 265-282. http://dx.doi.org/10.2190/FJH0-H8TN-YWF5-4557

[35] K. I. Hoffman, D. H. Demo and J. N. Edwards, "Physical Wife Abuse in a Non-Western Society: An Integrated Theoretical Approach,” Journal of Marriage and Family, Vol. 5, No. 6, 1994, pp. 131-146. http://dx.doi.org/10.2307/352709

[36] K. I. Hoffman, D. H. Demo and J. N. Edwards, "Physical Wife Abuse in a Non-Western Society: An Integrated Theoretical Approach,” Journal of Marriage and Family, Vol. 5, No. 6, 1994, pp. 131-146. http://dx.doi.org/10.2307/352709

[37] M. Koenig, M. B. Hassan, S. Ahmed and J. Haaga, "Individual and Community-Level Determinants of Domestic Violence in Rural Bangladesh,” H.P.C.P.P, 1999, p. 32.

[38] P. Orpinas, "Who Is Violent? Factors Associated with Aggressive Behaviours in Latin America and Spain,” Pan American Journal of Public Health, Vol. 5, No. 4-5, 1999, pp. 237-243.

[39] D. Levinson, "Violence in Cross-Cultural Perspective," Sage Publications, New-Bury Park, 1989, p. 139. 